\title{
The Future of Capitation
}

\section{The Physician Role in Managing Change in Practice}

John D. Goodson, MD, Arlene S. Bierman, MD, MS, Oliver Fein, MD, Kimberly Rask, MD, PhD,

Eugene C. Rich, MD, Harry P. Selker, MD, MSPH

\begin{abstract}
Capitation-based reimbursement significantly influences the practice of medicine. As physicians, we need to assure that payment models do not jeopardize the care we provide when we accept higher levels of personal financial risk. In this paper, we review the literature relevant to capitation, consider the interaction of financial incentives with physician and medical risk, and conclude that primary care physicians need to work to assure that capitated systems incorporate checks and balances that protect both patients and providers. We offer the following proposals for individuals and groups considering capitated contracts: (1) reimbursement for primary care physicians should recognize both individual patient encounters and the administrative work of patient care management; (2) reimbursement for subspecialists should recognize both access to subspecialty knowledge and expertise as well as patient care encounters, but in some situations, subspecialists may provide the majority of care to individual patients and will be reimbursed as primary care providers; (3) groups of physicians should accept financial risk for patient care only if they have the tools and resources to manage the care; (4) physicians sharing risk for patient care should meet regularly to discuss care and resource management; and (5) physicians must disclose the financial relationships they have with health plans and medical care organizations, and engage patients and communities in discussions about resource allocation. As a payment model, capitation offers opportunities for primary care physicians to influence the future of health care by improving the management of resources at a local level.
\end{abstract}

Received from Harvard Medical School, and Massachusetts General Hospital, Boston, Mass (JDG); Center for Outcomes and Effectiveness Research Agency for Health Care Policy and Research, Rockville, Md (ASB); Department of Clinical Medicine and Clinical Public Health, Weill Medical College of Cornell University, New York, NY (OF); Department of Medicine, Emory University School of Medicine, Atlanta, Ga (KR); Department of Medicine, Center for Practice Improvement and Outcomes Research, Creighton University School of Medicine, Omaha, $\mathrm{Neb}$ (ECR); and Division of Clinical Care Research, New England Medical Center, and Department of Medicine, Tufts University School of Medicine, Boston, Mass (HPS).

Address correspondence and reprint requests to Dr. Goodson: WAC 625, Massachusetts General Hospital, Boston, MA 02114 (e-mail: jgoodson1@partners.org).
KEY WORDS: capitation; physician reimbursement; physician organization; physician financial risk; universal health care access.

J GEN INTERN MED 2001;16:250-256.

A s practitioners, we are well aware of the monumental changes occurring in our workplace, be it the office, the clinic, or the hospital. We have witnessed the expectations for health care reform rise and fall as efforts to develop and enact the Clinton Health Plan gripped the country from early 1993 to the late summer of $1994 .^{1}$ We have shared the national concern about the cost of health care; we have watched as corporate profits have been created through hospital consolidation and the marketing of health care ${ }^{2}$; and we have worried, in our private moments, about whether our work, which has been fundamentally based on personal encounters, will have the same value to us and to our patients in the future.

This report represents the work of a task force established within the Society for General Internal Medicine Health Policy Committee. Our intent was to clarify our own understanding of how capitation might be adapted to improve the care of our patients. First, we reviewed the literature concerning financial incentives in clinical practice. Second, we examined the impact of capitation on a variety of risks-patients' health risks, society's financial risk, and physicians' financial risk. Third, through a process of drafting, review, and final consensus, we developed a series of proposals designed to help physicians and physician groups as they discuss approaches to capitation.

Ample evidence suggests that physicians respond to economic incentives in their practices. In fee-for-service (FFS) practices, physicians tend to order more tests. ${ }^{3,4}$ consultations, ${ }^{5}$ elective procedures, ${ }^{6,7}$ and hospitalizations. $^{8,9}$ When physicians have ownership of consulting services, their rates of utilization of these ancillary services are higher. ${ }^{10,11}$ HMOs which reimburse physicians on a FFS basis are associated with higher rates of hospitalization than those which use capitation. ${ }^{12}$ In capitated practices, patients have fewer overall hospitalizations, ${ }^{13}$ see specialists less often, ${ }^{14}$ and may underuse quality monitoring for chronic illness while more intensively monitoring areas of potential overuse, such as cesarean 
delivery rates. ${ }^{15}$ Recognizing the impact of reimbursement on physician practice, we sought to develop proposals that blunt the overuse incentives of FFS and the underuse incentives of capitation.

\section{CAPITATION AND THE SHIFTING LOCUS OF RISK}

As practicing physicians, our work demands that we manage a number of concurrent risks. Our foremost responsibility is to manage the individual health risks of our patients, be they risks associated with lifestyle, predisposition to illness, or diagnosed conditions. We also have a broader social responsibility ${ }^{16-18}$ to prudently use the resources society allocates to health care, society's financial risk. Finally, we face personal financial risk from decisions made by ourselves and others. Every physician reimbursement model poses different distributions of these risks: patient health risk, society's financial risk, and physician financial risk.

Our heritage as medical practitioners is based on the payment for service around the individual encounter (i.e., FFS). In contrast, capitation dissociates physician reimbursement from the patient encounter. ${ }^{19-22}$ An organization, a group of practitioners, or a single physician contracts to deliver care for the individual patient for a defined interval of time. Payment is made prospectively on a "per-member-per-month" (PMPM) basis for a contracted number of months.

Capitation has the potential to increase patient health risk $^{15,23,24}$ because there are incentives to reduce services and incentives to defer care beyond the prepayment interval. Counterbalancing these incentives are the theoretical incentives to invest in medical care that can decrease long-term medical costs through disease prevention and early treatment. Practices reporting a larger proportion of income from capitated contracts are more likely to base primary care physician compensation on measures of quality and utilization. ${ }^{25}$ Unfortunately, the incentives to make these investments are mitigated by the relatively high rates of turnover, as patients move from plan to plan, precluding long-term financial benefit. ${ }^{26}$ Society's financial risk is minimal in the short term. In the long term, society may save money if capitation results in increased investments in prevention and early treatment, or society may lose money if delayed care produces more expense. Physician personal financial risk can be high, particularly if a few patients develop high cost illness. ${ }^{27}$ Since financial risk is transferred to the physician level, there are financial disincentives for a physician or a group to take on the care of complex or chronically ill patients. ${ }^{26}$ The incentive to avoid patients who are likely to have high per capita costs during the contract interval is only partially buffered by risk adjustment or "stop-loss" insurance. In groups where physicians pool risk, incomes become highly interdependent, adding another level of complexity. Knowing that your clinical decisions might adversely affect the incomes of your colleagues could influence decision making and adversely affect patient care.

\section{TWO-TIERED AND THREE-TIERED CAPITATION}

A distinction can be made between 2-tiered and 3-tiered capitated payments. With 2 -tiered capitation, a health plan contracts directly with a physician, who is then paid on a PMPM basis. The financial benefits and risks associated with caring for a panel of patients flow directly to the physician. Under 3-tiered capitation, the plan contracts with an intermediary group that in turn has considerable latitude over how physicians are paid, ${ }^{19}$ either by capitation, FFS, salary, or a combination. The advantages of 3-tiered capitation are increased flexibility in physician payment modeling, enhanced physician leverage in contract negotiations with payers, and standardization of information systems. However, these advantages may require additional administrative costs and investments.

Factors further influencing the impact of capitation on a practice and its patients include: (1) the size of the group of patients for whose costs the physician is assuming financial risk; (2) the patient's "risk group"28 as defined by diagnoses; (3) the scope of capitated services; (4) other physician incentives in place (both financial and nonfinancial) ${ }^{29}$; (5) the adequacy of the capitated payments including whether they are "riskadjusted" for disease type and/or severity ${ }^{30-32}$; (6) protections against undue financial $\mathrm{risk}^{22}$; (7) the proportion of practice revenue derived from capitation ${ }^{22}$; and (8) the availability of savings (if any) from cost efficiency for use to improve services.

\section{RISK ADJUSTMENT: REDUCING PHYSICIAN FINANCIAL RISK}

\section{Risk Adjustment}

Risk adjustment ${ }^{32-35}$ is one of the major challenges of capitation. Capitated payments are typically based on average costs of care. However, costs of care are directly related to health status. For example, under FFS, an elderly Medicare beneficiary reporting poor health will have subsequent Medicare annual expenditures 5 times greater than that of a beneficiary reporting excellent health, although their capitated payments would be the same if they were the same age and gender and lived in the same area. ${ }^{31}$ As a result, practices that care for sicker patients could encounter substantial losses. Because of this "adverse" selection, unintended incentives to withhold services can evolve. ${ }^{30}$

Risk adjustment is used to address predictable differences in the costs of care. ${ }^{32,35,36}$ Age, gender, diagnosis (inpatient and/or outpatient), or health status information have been used. Risk adjustment systems developed for use by Medicare and Medicaid ${ }^{29,36}$ are intended to limit overpayment or underpayment for plan 
enrollees resulting from health status differences. ${ }^{37,38}$ However, these risk adjusters all have limitations. ${ }^{34,39}$ While they may reduce financial incentives to enroll only healthier patients at the health plan level, they may not be adequate to protect against variation in costs at the physician or small-group practice level because much of this variation is unpredictable. ${ }^{29}$ For example, the 1992 mean annual expenses for Medicare patients with coronary artery disease ranged from $\$ 1,702$ to $\$ 19,959$, depending on additional comorbidity. ${ }^{31}$

\section{Loss Limits}

Even if risk adjusters are used, physicians still need protection against undue financial risk arising from patients who incur unpredictably high-cost illnesses. Reinsurance, "stop-loss" clauses, and "risk corridors" have all been employed for this purpose. ${ }^{27}$ Reinsurance typically covers the cost of care for a patient or group of patients whose costs exceed a given specified amount. "Stop-loss" clauses can be incorporated into capitation contracts to achieve the same goal by covering individual expenses beyond established thresholds. ${ }^{22}$ "Risk corridors" set limits on the dollar amount of risk or gain that may be experienced for individual patients, e.g., $10 \%$ to $20 \%$ above or below capitation payments. Unfortunately, many physicians who have capitated contracts lack these basic protections. $^{22}$

\section{Disease Carve-outs}

Disease "carve-outs" can also be used to limit risk by narrowing the range of services covered under a capitated care contract. With carve-outs, specific services (e.g., mental health, substance abuse) or care of specific disease conditions (e.g., AIDS, cancer, heart failure) are provided by designated providers under contract with the health plan or physician group. While potentially beneficial in some circumstances, in other circumstances carve-outs can fragment care, undermine the physician-patient relationship, and provide disincentives for generalist physicians to provide comprehensive care. In the worst cases, carve-outs become a tool to limit access by making the referral process awkward or inconvenient. ${ }^{40}$

\section{Panel Size}

Establishing the minimum patient panel size for accepting risk is problematic. Capitated payments to small groups or individual doctors, for the most part, violate the law of large numbers, whereby low risk individuals balance those at high risk. ${ }^{28}$ Evaluating a "safe" level of risk for a practice requires the weighing of several factors: (1) the type of practice (primary care vs specialty care); (2) the severity of illness and the need for health care, the "casemix"; (3) the scope of capitation (risk for own services vs risk for own services as well as ancillary services, hospitalization expenses, and specialty care); (4) the level of "stop-loss" coverage or reinsurance; (5) the proportion of practice revenue covered by the contract; and (6) the historical variability in patient expenditures for the practice (practitioner-to-practitioner variability). Most analysts agree that a prudent incentive structure should not link an individual doctor's financial well-being tightly to a specific choice for a specific patient, arguing that the risk pool in capitated arrangements should be larger than individual physician's practices. ${ }^{20}$ Also, it is difficult for small practices to have the financial reserves or access to capital outside the practice to enable them to invest in the information systems needed to track resource use. Despite all this, many physicians accept such financial risk contracts, even though they are less satisfied with the care they provide. ${ }^{41}$ Although large physician practices are most likely to hold capitated contracts, a 1995 survey found that one fourth of solo practitioners and approximately one third of those in practices with 2 to 5 physicians accepted capitated contracts. ${ }^{20}$ American Medical Association data from 1997 show that the percentage of practice income from capitated contracts was $9 \%$ for internal medicine and $13 \%$ for family practice. ${ }^{42}$

In summary, there are many elements affecting the structure of capitated compensation arrangements, each with differing financial incentives, each exposing patients, society, and ourselves as physicians to different risks. Our challenge is to manage these risks to the best of our abilities, keeping paramount our responsibilities to the individual patient to provide care with the resources allocated without exploiting the system for personal financial gain.

\section{CAN WE USE CAPITATION TO IMPROVE PATIENT CARE?}

Cost containment efforts will continue to drive changes in health care as employers, state and federal governments, and other payers demand more restraint of expenditures. Physicians have a central role, but that role may take 2 forms. Physicians may become de facto employees of health care delivery organizations and deliver care according to external regulation, or physicians may proactively develop the collaborative relationships that will allow them to practice good medicine, achieve efficiencies in care delivery, and substantially influence the organizations in which they practice. Believing that our work as physicians is central to the success of health care delivery in our society, the task force members favor a proactive approach, beginning with and rooted firmly in a commitment to patient care, collaboration with professional colleagues, and participation in practice operations.

There is a compelling economic logic to capitation because it allows many different types of payers to prospectively individualize payment for health care, ${ }^{43-45}$ but there are tremendous challenges to the process of pooling financial risk at the practice level. Ideally, riskadjusted capitated payments will be developed to reflect 


\section{Table 1. Assessing Capitation Arrangements: Critical Questions for Physicians to Consider}

What is the size of the risk group?

What services are capitated?

What services are "carved out?"

Are payments risk-adjusted?

If so, what risk adjustment methodologies are used?

Do they reflect workload and actual costs of care?

What protections against undue risk such as "stop loss" clauses or reinsurance are in place?

At what level of hospital-based care do these begin?

At what level of ambulatory-based care do these begin?

Is information about patient resource utilization readily available and accurate?

Will the practice be able to know how much is expended for patient care?

What happens if there is revenue beyond expenses?

Will these resources be available to expand or improve patient care?

the higher costs for individual physicians or practices who disproportionally care for sicker patients. Because even the best available risk adjustment procedures can explain only part of the variation in an individual's medical costs, the financial viability for physicians or groups is dependent on the ability to pool risk over a sufficient number of patients. Table 1 outlines a series of critical questions physicians should ask as they assess potential capitation arrangements.

Although we remain concerned about the conflicts inherent in capitation and its potential threats to our patients and our profession, we also recognize the opportunities of capitation to improve patient care, and offer the following proposals for groups of physicians organizing capitated reimbursement (see Fig. 1):

\section{Reimbursement for primary care physicians} should recognize both individual patient encounters and the administrative work of patient care management.

We favor reimbursement for individual primary care physicians that recognizes the dual nature of our work. We have a responsibility to manage the personal health risks of our patients with the resources available. Therefore, a portion of our personal reimbursement should be related to our success in managing care within a budget. Conversely, we have a responsibility to be accessible to our patients. ${ }^{46,47}$ Therefore, a portion of our reimbursement should be related to the provision of personal professional services to patients.

In practice, a group would have 2 concurrent physician compensation mechanisms, one based on patient panel size (perhaps $20 \%$ to $40 \%$ of budgeted funds) and made on a per capita basis and another based on patient care encounters (perhaps $60 \%$ to $80 \%$ of budgeted funds), with a practice-specific formula that pays for each visit. In most cases, relative value units (RVUs) could be used as the currency of encounter-based care. The proportion of physician income derived from the 2 reimbursement sources should be balanced so that the payment associated with care management is sufficient to compensate nonencounter activities. For example, is the payment such that a practicing physician will have enough paid time to answer phone or electronic patient care messages? Is the payment associated with each encounter sufficient to compensate for patient care? Is the payment such that a physician will add an extra patient to the schedule?

2. Reimbursement for subspecialists should recognize both access to subspecialty knowledge and expertise as well as patient care encounters.

Capitated payment for subspecialty care can produce indistinct boundaries of responsibility between the primary physician and the subspecialist.

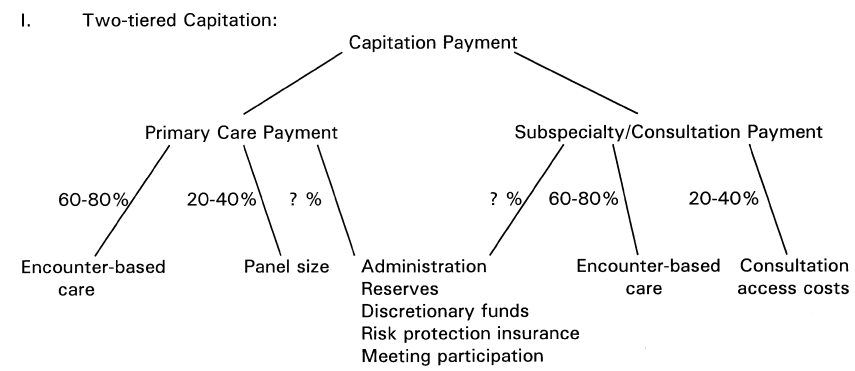

II. Three-tiered Capitation:

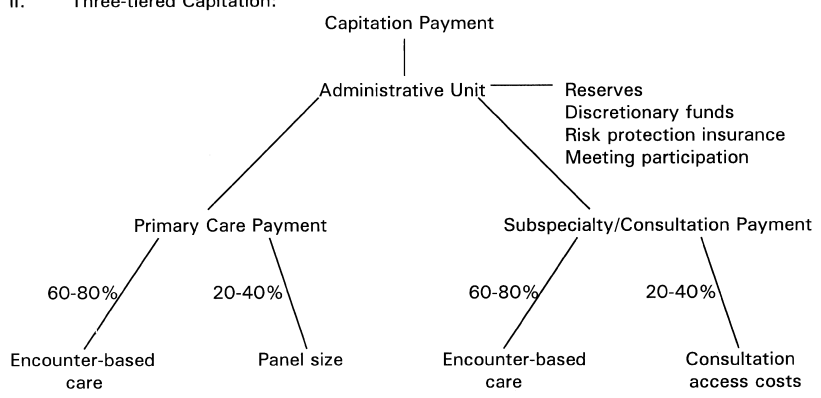

FIGURE 1. Simplified capitation reimbursement models, excluding hospital and institutional costs, pharmacy costs, medical device costs, facility costs, and home care costs. Consultation access costs are capitated payments to subspecialists/ consultants to be available for informal consultation (electronic) and comanagement discussions with primary care physicians. Discretionary funds are the portion of capitated payment set aside for care innovation beyond covered services or procedures. Encounter-based care is care reimbursement based on relative value units (RVUs) of care. Meeting participation is defined as payments made to physicians for participation in care management meetings. Panel size is the number of patient-months of care. Reserves are funds that are held back to cover payment delays, seasonal variations in operational expenses, etc. Risk protection insurance is coverage for unexpected costs associated with patient care or visit volume and is also known as "stop-loss" reinsurance. 
As a result, patients may end up without a physician who is responsible for their care. Alternately, subspecialty care can be reimbursed on an encounter basis or on an illness episode basis. In either case, primary physicians may be in an awkward position when seeking informal consultation or educational advice from colleagues, without specifically making a referral.

Therefore, we favor a hybrid reimbursement mechanism for subspecialty care that recognizes the need for both informal and formal consultation, i.e., both availability to discuss patient care by phone, letter, or electronic media, and availability for direct patient care. Such a system should pay for consultation access by "retainer" reimbursement (perhaps $20 \%$ to $40 \%$ of budgeted funds), and for each patient encounter or illness episode by direct payment (perhaps $60 \%$ to $80 \%$ of budgeted funds). Again, RVUs could be used as the currency of encounter-based care. In practice, a group might have 2 specialty reimbursement mechanisms, one based on the amount of time the consultant is expected to be available (such as hours per week) and one based on patient encounters, with a practice-specific formula that pays for each visit.

The proportion of compensation derived from the 2 payment sources should be balanced so that the payment associated with knowledge access (consultation access) is sufficient to compensate subspecialists for the comanagement of complex patients. For example, does the subspecialist lay out a care plan and then help to solve problems by letter, phone, or electronic media? Is the payment associated with individual consultations sufficient to compensate for direct patient care? Is the subspecialist willing to add an extra patient to the schedule?

We recognize that for some patients (e.g., oncology patients), the principal care responsibility will be carried by the subspecialist delivering the majority of care. In these cases, direct capitation payment with appropriate risk adjustment should be made to the subspecialist. A portion of the capitation payment could then be allocated to encounter-based primary care.

3. Groups of physicians should accept financial risk for patient care only if they have the tools and resources to manage the care.

We should resist accepting financial risk without a commitment from our subspecialty peers to the necessary collaborative relationships and from our organizations to provide information support. ${ }^{19}$ This should include timely reports about resources allocated and available, logistical support of the practice organization, access to resources for innovation in patient care, a mechanism to assure that allocated resources are indeed adequate, and protection from excessive risk arising from the care of patients with catastrophic injury or illness. We should not accept payment models which create apprehension that caring for the sickest patients will threaten the financial viability of our practices.

4. Physicians sharing risk for patient care should meet regularly to discuss clinical care and resource management.

Aggregating financial risk requires that we work together with our peers to manage each patient to the best of our skill without depleting aggregate resources. Developing groups composed of those physicians who share financial risk to review clinical care and resource allocation decisions represents a substantial change in the way we think about our professional work. It implies a greater day-to-day dialogue among colleagues about the details of patient care and ways to improve both the quality and efficiency of our work. Such group resource management will only thrive with the evolution of a practice-based culture of collaboration. Reimbursement must be sufficient to encourage active and meaningful participation. Any unused resources should be used as a discretionary fund under the control of collaborating practitioners and available for care innovation and extension.

5. Physicians must disclose the financial relationships they have with health plans and medical care organizations and actively engage patients and communities in discussions about resource allocation.

Given the evidence that physician practice is strongly influenced by financial incentives, ${ }^{5-13,48-56}$ patients have the right to know the financial constraints under which their physician practices. Survey data have indicated that patients usually do not know how their physicians are compensated and that $76 \%$ of respondents think that a bonus paid for ordering fewer tests would adversely affect the quality of care. ${ }^{57}$ To the degree that capitation provides physicians with financial incentives to restrict patient care, patient trust in physician decision making, though not clearly measurable, ${ }^{58}$ may be undermined. Among physicians, there is an increasing awareness that financial concerns can unsettle the patient-physician relationship. ${ }^{59}$ The criteria developed by the American College of Physicians to guide our professional relationships with the pharmaceutical industry can be applied to our new relationships with capitated health care payments. "Would you be willing to have these relationships openly known?"60

Ultimately, there will be difficult decisions about limiting access to certain unproven therapies or balancing the costs of one intervention against another. Since the costs of care are ultimately borne by employers, workers, and taxpayers, we should 
actively enlist members of society in these decisions. We should not allow this role to be assumed by corporate and financial representatives or even by physicians themselves. We should encourage the participation of patients in the decision-making process. ${ }^{46,47,57}$ Although health care delivery is complex, expensive, and bureaucratic, patients and communities should be involved in discussions of resource allocation.

Our proposals are a beginning point for discussions that need to develop within individual practices and the community of primary care physicians. Many questions are left unanswered by our deliberations and in the published literature. Our goal has been to assess the reported experience and to promote an expanded discussion of capitation in the medical community.

\section{USING THE CAPITATION EXPERIENCE TO IMPROVE ACCESS}

The patient care coordination skills developed as a necessity from sharing capitated risk may improve our care for those with insurance, but there remains the challenge of caring for the uninsured. As physicians, we should not maintain a health delivery system that segregates our patients by the presence or absence of health insurance coverage. Almost a quarter of those with whom we share virtually all other resources including the economy, the environment, and the educational system are excluded from routine health care because they are uninsured or underinsured. Our active participation in the development of capitated reimbursement, specifically the local application of the incentives of capitation in our own practices and the development of new forms of collaborative care and resource management, needs to be coupled with a simultaneous commitment to extend health care access to all members of our society. Responsible efforts to manage health care efficiently and effectively will be an essential component of any system of universal access. Improving the management of health care resources for the insured should free resources to help care for the disenfranchised and allow society to more accurately calculate and manage the costs of providing universal health care.

\section{CONCLUSIONS}

Capitation affects all aspects of medical practice. It has the potential to clarify the boundaries between primary care physicians and their consulting subspecialist colleagues. It will certainly expand the financial risks faced by all practitioners. It will probably force changes in the allocation of health care resources, perhaps leading to a more accurate determination of true costs. Realistically, the necessary conditions for capitation to function as an acceptable and sustainable reimbursement model may never be achieved. Our task is to actively participate in the reengineering of health care delivery while maintaining our personal and professional standards in order to create a system that will work for everyone in our society.

The views expressed by Dr. Bierman do not necessarily represent the position of the Agency for Health Care Policy and Research or the Department of Health and Human Services.

Dr. Fein is the Co-Principal Investigator on Partnerships in Quality Education, funded in part by the Pew Charitable Trusts, Inc.

We want to acknowledge the assistance of Ms. Linda Paciulan in manuscript preparation. The following have reviewed and assisted in the preparation of this report: Drs. Andrew Bindman, Carolyn Clancy, Gordon Schiff, David Parish, Mark Leibow, Yen-Ping Chiang, and Mattew Wynia.

\section{REFERENCES}

1. Blumenthal D. Health care reform - past and future. N Engl J Med. 1995;332:465-8.

2. Relman AS. The Health Care Industry: Where is it taking us? N Engl J Med. 1991;325:854-8.

3. Epstein AM, Begg CB, McNeil BJ. The use of ambulatory testing in prepaid and fee-for-service group practices. N Engl J Med. 1986;314:1089-94.

4. Murray JP, Greenfield S, Kaplan SH, Yano EM. Ambulatory testing for capitation and fee-for-service patients in the same practice setting: Relationship to outcomes. Med Care. 1992;30:252-61.

5. Clement DG, Retchin SM, Brown RS, et al. Access and outcomes of elderly patients enrolled in managed care. JAMA. 1994;271: 1487-92.

6. Ransom SB, McNeeley GS, Kruger ML, et al. The effect of capitated and fee-for-service remuneration on physician decision making in gynecology. Obstet Gynecol. 1996;87:707-10.

7. Goldzweig CL, Mittman BS, Carter GM, et al. Variations in cataract extraction rates in medicare prepaid and fee-for-service settings. JAMA. 1997;277:1765-8.

8. Greenfield S, Nelson E, Zubkoff M, et al. Variations in resource utilization among medical specialties and systems of care. JAMA. 1992;267:1624-30.

9. Miller RH, Luft HS. Managed care plan performance since 1980. JAMA. 1994;271:1512-8.

10. Mitchell JM, Sunshine JH. Consequences of physicians' ownership of health care facilities - joint ventures in radiation therapy. N Engl J Med. 1992;327:1497-500.

11. Swedlow A, Johnson G, Smithline N, et al. Increased costs and rates of use in the California workers' compensation system as a result of self-referral by physicians. N Engl J Med. 1992;327: 1502-6.

12. Hillman AL, Pauly MV, Kerstein JJ. How do financial incentives affect physicians' clinical decisions and the financial performance of health maintenance organizations? N Engl J Med. 1989;321: 86-92.

13. Manning WG, Leibowitz A, Goldberg GA, et al. A controlled trial of the effect of a prepaid group practice on use of services. N Engl J Med. 1984;310:1505-10.

14. Cooper RF, Nicholes LM, Tayler, AK. Patient choice of physician: Do health insurance and physician characteristics matter? Inquiry. 1996;33:237-46.

15. Kerr EA, Mittman BS, Hays RD, Leake B, Brook RH. Quality assurance in capitated physician groups. Where is the emphasis? JAMA 1996;276:1236-9.

16. Sulmasy DP. Physicians, cost control, and ethics. Ann Intern Med 1992;116:920-6. 
17. Dougherty CJ. Ethical values at stake in health care reform. JAMA. 1992;268:2409-12.

18. Emanuel L. Bringing market medicine to professional account. JAMA. 1997;277:1004-6.

19. Berwick DM. Payment by capitation and the quality of care. N Engl J Med. 1996;335:1227-31.

20. Hillman AL. Health maintenance organizations, financial incentives, and physicians' judgments. Ann Intern Med. 1990;112: 891-4.

21. Selker HP. Capitated payment for medical care and the role of the physician. Ann Intern Med. 1996;124:449-51.

22. Simon CJ, Emmons DW. Physician earnings at risk: an examination of capitated contracts. Health Aff (Millwood). 1997;16:120-6.

23. Swartz K, Brennan T. Integrated health care, capitated payment, and quality: The role of regulation. Ann Intern Med. 1996;124: 442-50.

24. Pearson SD, Sabin JE, Emanuel EJ. Ethical guidelines for physician compensation based on capitation. N Engl $\mathrm{J}$ Med. 1998;339:689-93.

25. Pedersen CA, Rich EC, Kralewski J, Feldman R, Dowd B, Bernhardt TS. Primary care physicians incentives in medical group practices. Arch Fam Med. 2000;9:458-62.

26. Shortell SM, Waters TM, Clarke KW, Budetti PP. Physicians as double agents. JAMA. 1998;280:1102-8.

27. Bodenheimer TS, Grumbach K. Capitation or decapitation. JAMA. 1996;276:1025-31.

28. Grumbach K, Osmond D, Vranizan K, Jaffe D, Bindman AB. Primary care physicians' experience of financial incentives in managed-care systems. N Engl J Med. 1998;339:1516-21.

29. Ingber MJ. The current state of risk adjustment technology for capitation. J Ambulatory Care Manage. 1998;21:1-28.

30. Bierman AS, Bubolz TZ, Fisher ES, Wasson JH. How well does a single question about health predict the financial health of Medicare managed care plans? Eff Clin Pract. 1999;2:56-62.

31. McNamara RL, Powe NR, Shaffer T, Thiemann D, Weller W, Anderson G. Capitation for cardiologists: accepting risk for coronary artery disease under managed care. Am $\mathrm{J}$ Cardiol. 1998;82:1178-82.

32. Newhouse JP, Buntin MB, Chapman JD. Risk adjustment and Medicare: taking a closer look. Health Aff (Millwood). 1997; 16:26-43.

33. Kipp RA, Towner WC, Levin HA. Financial and actuarial issues. In: Disease Management: A Systems Approach to Improving Patient Outcomes. Chicago: American Hospital Pub; 1997.

34. Newhouse J, Buntin M, Chapman J. Risk Adjustment and Medicare. New York: Commonwealth Fund Publication; 1999.

35. Kuttner R. The risk-adjustment debate. N Engl J Med. 1998; 339:1952-6.

36. Kronick R, Beyer JD. Paying plans to care for people with chronic illness. In: Kronick R, Beyer JD, eds. Medicare HMOs: Making Them Work for the Chronically Ill. Chicago: Health Administration Press; 1999:27-68.

37. Fowles JB, Weiner JP, Knutwon D. Taking health status into account when setting capitation rates. JAMA. 1996;276: 1316-22.

38. Newhouse JP, Manning WG, Keeler EB. Adjusting capitation rates using objective health measures and prior utilization. Health Care Financ Rev. 1989;10:41-54.

39. Iezzoni LI, Ayanian JZ, Bates DW, Burstin HR. Paying more fairly for Medicare capitated care. N Engl J Med. 1998;339:1933-8.
40. Jellinek MS and Nurcombe B. Two wrongs don't make a right, managed care, mental health, and the marketplace. JAMA. 1993;270:1737-9.

41. Kerr EA, Hays RD, Mittman BS, Siu Al, Leake B, Brook RH. Primary care physicians' satisfaction with quality of care in California capitated medical groups. JAMA. 1978;278:308-12.

42. Center for Health Policy Research (American Medical Association). Physician Marketplace Statistics. Profiles for Detailed Specialties, Selected States and Practice Arrangements/AMA Center for Health Policy Research. Chicago: American Medical Association; 1998.

43. Gold MR, Hurley R, Lake T, Ensor T, Berenson R. A national survey of the arrangements managed-care plans make with physicians. N Engl J Med. 1995;333:1678-82.

44. Robinson JC, Casalino LP. The growth of medical groups paid through capitation in California. N Engl $J$ Med. 1995;333: 1684-8.

45. Iglehart JK. Physicians and the growth of managed care. N Engl J Med. 1994;332:1167-72.

46. Emanuel EJ, Dubler NN. Preserving the physician-patient relationship in the era of managed care. JAMA. 1995;273:323-8.

47. Leopold N, Cooper J, Clancy C. Sustained partnership in primary care. J Fam Pract. 1996;42:129-37.

48. Safran DG, Tarlov AR, Rogers WH. Primary care performance in feefor-service and prepaid health care systems. JAMA. 1994;271: 1579-86.

49. Conrad DA, Maynard C, Cheadle A, et al. Primary care physician compensation method in medical groups. Does it influence the use and cost of health services for enrollees in managed care organizations? JAMA. 1998;279:853-8.

50. Greenfield S, Rogers W, Mangotich M. Outcomes of patients with hypertension and non-insulin-dependent diabetes mellitus treated by different systems and specialties. JAMA. 1995;274:1436-44.

51. Lurie N, Christianson J, Finch M. The effects of capitation on health and functional status of the Medicaid elderly. Ann Intern Med. 1994;120:506-11.

52. Yelin EH, Criswell LA, Feigenbaum PG. Health care utilization and outcomes among persons with rheumatoid arthritis in fee-forservice and prepaid group practice settings. JAMA. 1996;276: 1048-54.

53. Brook RH, Ware JE, Rogers WH, et al. Do free care improve adults' health? N Engl J Med. 1983;309:1426-33.

54. Siu AL, Sonnenberg FA, Manning WG, et al. Inappropriate use of hospitals in a randomized trial of health insurance plans. N Engl $\mathrm{J}$ Med. 1986;315:1259-66.

55. Ware JE Jr, Rogers WH, Davies AR, et al. Comparison of health outcomes at a health maintenance organization with those of feefor-service care. Lancet. 1986:1017-22.

56. Ware JE, Bayliss MS, Rogers WH, et al. Differences in 4-year health outcomes for elderly and poor, chronically ill patients treated in HMO and fee-for-service systems. JAMA. 1996;276:1039-47.

57. Kao AC, Zaslavsky AM, Green DC, Koplan JP and Cleary PD. Physician incentives and disclosure if payment methods to patients. J Gen Intern Med. 16:181-8.

58. Pearson SD and Racke LH. Patients' trust in physicians: many theories, few increases, and little data. J Gen Intern Med. 2000; 15:509-13.

59. Am College of Phy. Physicians and the pharmaceutical industry. Ann Intern Med. 1990;112:624-6.

60. Levinson W. Paid not to refer? J Gen Intern Med. 16:209-10. 